\title{
Action protéolytique d'un enzyme coagulant* comparée à celle de la présure
}

\author{
par \\ J. L. MAUBOIS et G. MOCQUOT \\ Laboratoire de Recherches de Technologie Laitière, I.N.R.A. (35) Rennes \\ Station Centrale de Recherches Laitières et de Technologie des Produits \\ Animaux, C.N.R.Z. - I.N.R.A. (78) Jouy-en-Josas
}

(avec la collaboration technique de M. PIOT et de H. GOUDEDRANCHE)

La coagulation proprement dite du lait par la présure s'accompagne d'une protéolyse rapide mais limitée ; les fragments ainsi détachés de la caséine par la présure ont fait l'objet depuis 15 ans de nombreuses études (Garnier et al., 1968).

A cette phase de protéolyse limitée succède une phase de protéolyse plus lente que l'on a appelée, par opposition à la précédente, phase de protéolyse générale ou non spécifique (Kosikowski et Mocquot, 1958 ; Ledford et al., 1966 ; Ledford et al., 1968).

$\mathrm{Au}$ cours des différentes étapes de la transformation du lait en fromage, ces deux phases se succèdent. Au cours de la première phase la protéolyse vient diminuer de quelques 3 ou 4 pour 100 la quantité de fromage que l'on pourrait s'attendre à obtenir à partir d'une quantité déterminée de caséine. Cette phase débute au moment de l'addition de l'enzyme et se termine lorsqu'intervient la séparation (synérèse) entre le caillé et le lactosérum aussitôt après la coagulation. La seconde phase lui succède et se poursuit pendant le reste de la fabrication et au cours de la maturation du fromage (d'autres enzymes, le plus souvent d'origine microbienne ou fongique, intervenant eux aussi) (Kosikowski et Mocquot, 1958).

Un nouvel enzyme, destiné à se substituer à la présure, étant actuellement proposé pour la coagulation du lait et la fabrication de fromage (Sardinas, 1966 ; Naudts, 1967 ; Alais et Novak, 1968 ; Ramet et al., 1969 ; Sardinas, 1968) il a paru utile d'examiner le rôle qu'il pouvait jouer en le comparant à celui bien connu de la présure.

* Préparation enzymatique, extraite du champignon Endothia parasitica et commercialisée sous le nom de "Sure Curd ", aimablement mise à notre disposition par PFIZER EUROPE (Lot 74575). 


\section{MATERIEL ET METHODES}

\section{Obtention du lactosérum}

Le lait du troupeau de la ferme de La Harpe était écrémé puis " thermisé » à $70^{\circ} \mathrm{C}$ pendant $2 \mathrm{mn}$. Le lait refroidi était divisé en deux portions, chacune de $2000 \mathrm{~g}$. Les portions étaient versées dans deux béchers, puis portées à $30^{\circ} \mathrm{C}$ et additionnées de $2 \mathrm{p} .100$ d'un levain lactique composé d'une souche de Streptococcus lactis $\left(\mathrm{C}_{2}\right)^{*}$ et d'une souche de Streptococcus cremoris $\left(\mathrm{E}_{\mathrm{s}}\right)^{*}$. Après un mélange soigneux, on prélevait $100 \mathrm{~g}$ de lait dans chacun des deux béchers pour l'analyse.

Les deux béchers étaient maintenus à $30^{\circ} \mathrm{C}$ et, lorsque le $\mathrm{pH}$ du lait ensemencé atteignait une valeur voisine de 6,4 , on ajoutait $0,4 \mathrm{ml}$ d'une solution de présure de veau** liquide du commerce (force $1 / 10000$ ) dans un des béchers ; dans l'autre, la quantité d'enzyme extrait d'Endothia parasitica et commercialisé sous la marque Sure Curd (SC) nécessaire pour obtenir un «temps de prise » du lait aussi voisin que possible de celui additionné de présure. Lorsque le coagulum atteignait la consistance recherchée (en général 60 à $65 \mathrm{mn}$ après l'emprésurage), il était moulé à la louche, selon la technique en usage dans les fromageries de Camembert et cette technique était également suivie au cours des opérations ultérieures.

Dans un premier type d'essai, le lactosérum qui s'égouttait était recueilli par fractions successives d'environ $100 \mathrm{ml}$ chacune. Ces fractions étaient pesées et immédiatement analysées.

Dans un second type d'essai, on laissait le lactosérum s'égoutter en totalité et on procédait alors aux analyses sur le lactosérum recueilli.

Depuis le moment de l'addition du levain lactique jusqu'à celui de l'obtention des fractions (ou de la totalité) du lactosérum, le degré hygrométrique de l'atmosphère de la salle de fabrication était maintenu au voisinage de la saturation afin d'empêcher l'évaporation qui aurait amené une concentration du lait ou du lactosérum. En fait les différences de poids constatées au niveau du lait, du fromage et du lactosérum (bilan poids) étaient inférieures à 1 p. 100 .

\section{Détermination des matières azotées}

L'azote total était déterminé par microKjeldahl. On multipliait la teneur en azote par le coefficient 6,38 pour obtenir la teneur en matières azotées totales.

* Collection de la Station Centrale de Recherches Laitières. C. N. R. Z., Jouy-en-Josas.

** Etablissements BoLL (94) Vincennes. 
L'azote non protéique soluble dans l'acide trichloracétique à 12 p. 100 était déterminé immédiatement après l'obtention des fractions (ou de la totalité) du lactosérum et après 3 jours de conservation à $2^{\circ} \mathrm{C}$ selon White et Davies (1958).

\section{Dosage de la teneur en chlorure de sodium du lait et du lactosérum}

Après défécation du lait et du lactosérum par le ferrocyanure de zinc, les chlorures sont dosés dans le filtrat par la méthode du C.N.E.R.N.A. (Ann. Nutr. Aliment., 1951).

\section{Expression des résultats}

Si $\mathrm{n}_{\mathrm{L}}$ est la quantité totale de matières azotées contenue dans le lait mis en œuvre pour la fabrication avec la présure et avec l'enzyme SC.

Si $\mathbf{n}_{\mathrm{T}}$ est la quantité totale de matières azotées contenue dans le lactosérum « témoin » (présure).

Si $n_{\mathrm{E}}$ est la quantité totale de matières azotées du lactosérum « essai » (enzyme SC).

La proportion de matières azotées restant dans le fromage fabriqué avec la présure, $\mathrm{R}_{\mathrm{T}}$ est égale à :

$$
\mathrm{R}_{\mathrm{T}}=\frac{\mathrm{n}_{\mathrm{L}}-\mathrm{n}_{\mathrm{T}}}{\mathrm{n}_{\mathrm{L}}} \times 100
$$

La proportion de matières azotées restant dans le fromage fabriqué avec l'enzyme coagulant SC ou RE est égale à :

$$
\mathrm{R}_{\mathrm{E}}=\frac{\mathrm{n}_{\mathrm{L}}-\mathrm{n}_{\mathrm{E}}}{\mathrm{n}_{\mathrm{L}}} \times 100
$$

Mais, ainsi que nous l'avons récemment exposé (Maubois et Mocquot, 1967), la comparaison de $R_{T}$ et de $R_{E}$ n'a un sens que si les fromages fabriqués avec la présure d'une part et avec l'enzyme coagulant SC d'autre part, ont tous la même teneur en eau et si, en outre, partant d'un même poids de lait, on obtient le même poids total de lactosérum et de fromage avec la présure d'une part, avec l'enzyme SC d'autre part. C'est ce que nous avons obtenu dans les essais rapportés plus loin.

\section{RESULTATS}

Sur la figure 1 on a tracé, en fonction de la proportion de lactosérum écoulé, deux courbes représentant chacune les teneurs en matières azotées totales du lactosérum obtenu après coagulation du même lait ; l'une des courbes correspond à la coagulation par la présure, l'autre à la coagulation par l'enzyme SC. Sur cette même 
figure, est également indiqué en abscisses le nombre d'heures écoulé depuis l'addition des enzymes (point $\mathrm{O}, \mathrm{Emp}$. du graphique) ainsi que le $\mathrm{pH}$ de chaque lactosérum à un instant donné.

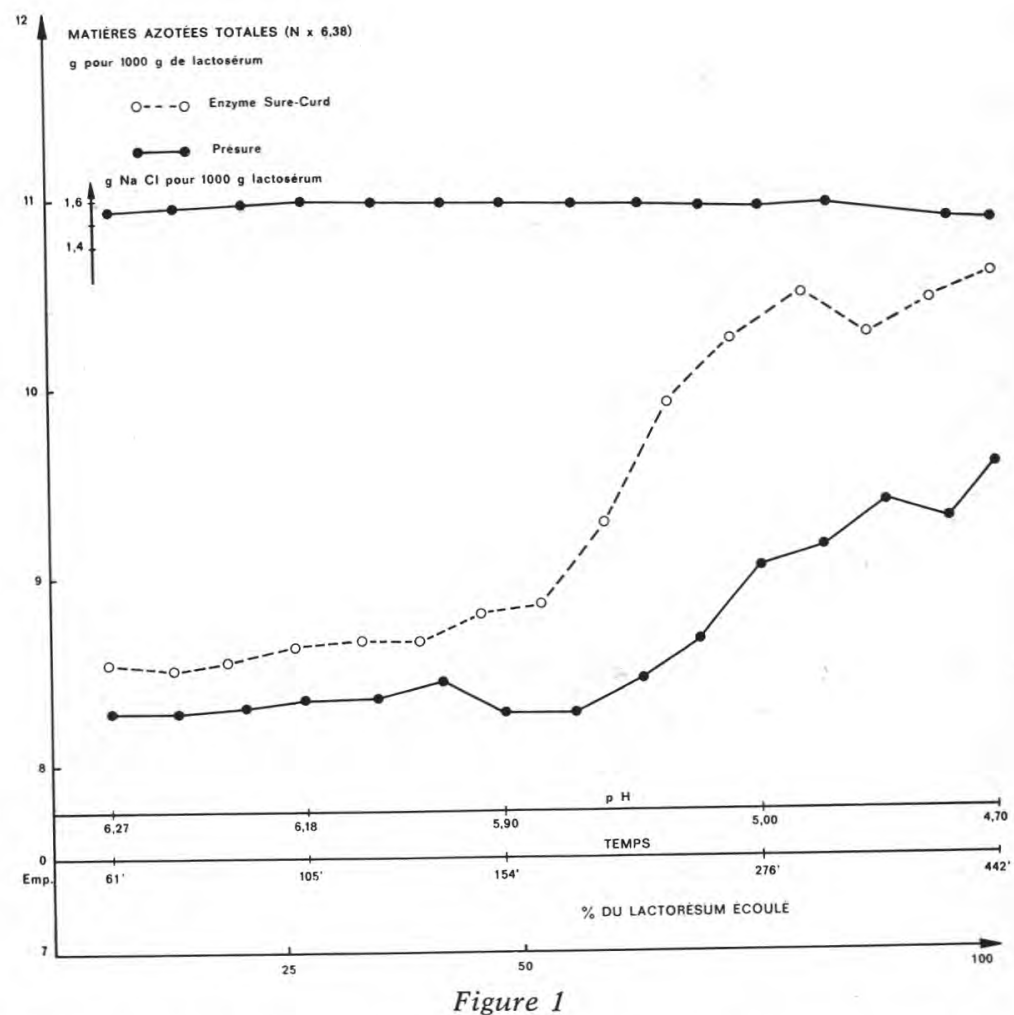

Enfin, on a également porté la teneur en chlorures (exprimée en $\mathrm{Cl} \mathrm{Na)} \mathrm{du} \mathrm{lactosérum} \mathrm{«présure} \mathrm{»} \mathrm{ou} \mathrm{«} \mathrm{SC} \mathrm{»} \mathrm{en} \mathrm{fonction} \mathrm{de} \mathrm{la} \mathrm{pro-}$ portion de lactosérum écoulé : la courbe obtenue correspond très sensiblement à une droite parallèle à l'axe des abscisses, indiquant ainsi l'absence d'évaporation appréciable au cours de l'égouttage ; donc les résultats traduisent bien la composition de chacun des lactosérum s'égouttant des coagulum.

La teneur en matières azotées totales du lactosérum obtenu après coagulation par l'enzyme SC est, dès le début de l'égouttage, un peu supérieure à celle obtenue avec la présure. La différence, selon les essais, est de 0,015 à $0,020 \mathrm{~g}$ de matière azotée pour $100 \mathrm{~g}$ de lactosérum. Elle reste sensiblement constante jusqu'au moment où près de 45 p. 100 du lactosérum s'est écoulé. Lorsque 60 p. 100 du lactosérum s'est écoulé, on observe une augmentation de la teneur en matières azotées totales du lactosérum présure. Mais cette augmentation est encore beaucoup plus marquée dans le cas du 
lactosérum SC. En fin d'égouttage, lorsque le pourcentage du lactosérum écoulé atteint 95 p. 100 du lactosérum total, les teneurs en matières azotées (pour $100 \mathrm{~g}$ de lactosérum) sont respectivement de $0,93 \mathrm{~g}$ dans le cas du lactosérum présure et de $1,05 \mathrm{~g}$ dans celui du lactosérum SC, soit une différence de 0,12 g de matière azotée entre les deux lactosérum.

Dans le tableau sont indiquées : a) dans les colonnes de gauche, les teneurs moyennes en matières azotées totales de deux essais où le lactosérum a été recueilli et analysé par fractions successives (essais 1 et 2 ) et la teneur en matière azotée d'un troisième essai où le lactosérum a été recueilli et analysé en une seule portion (essai 3); b) dans les colonnes de droite, les proportions des matières azotées totales du lait restant dans les fromages correspondants. On constate que les teneurs moyennes en matière azotée des lactosérum présure sont toujours inférieures à celles des lactosérum SC correspondants. La différence moyenne observée sur la totalité des lactosérum est de $0,06 \mathrm{~g}$ de matière azotée pour $100 \mathrm{~g}$ de lactosérum. Par voie de conséquence on constate que la proportion de matières azotées totales restant dans le fromage est toujours supérieure dans le cas de la présure à ce qu'elle est dans le cas de l'enzyme SC. La différence entre les deux varie suivant le lait employé de 1,3 p. 100 à 1,8 p. 100 [correspondant respectivement à 75,7 (présure) et $74,4(\mathrm{SC})$ et 79,6 (présure) et $77,8(\mathrm{SC})]$. Elle est égale à 1,6 p. 100 en moyenne pour les trois essais.

\begin{tabular}{|c|c|c|c|c|c|}
\hline \multirow[t]{2}{*}{$N^{o}$ des essais } & \multicolumn{2}{|c|}{$\begin{array}{l}\text { Teneur moyenne en } \\
\text { matières azotées } \\
\text { totales }(\mathrm{N} \times 6,38) \\
\text { du lactosérum } \\
(\text { en } \mathrm{g} \text { pour } 100 \mathrm{~g})\end{array}$} & \multicolumn{3}{|c|}{$\begin{array}{c}\text { Proportion des matières azotées } \\
\text { du lait restant dans les } \\
\text { fromages } \\
\text { (en p. 100) }\end{array}$} \\
\hline & $\mathrm{P}^{*}$ & $\mathrm{SC}^{* *}$ & $\mathrm{P}$ & SC & Différence \\
\hline Essai 1 & 0,865 & 0,939 & 79,6 & 77,9 & 1,7 \\
\hline Essai 2 & 0,819 & 0,890 & 79,6 & 77,8 & 1,8 \\
\hline Essai 3 & 0,855 & 0,900 & 75,7 & 74,4 & 1,3 \\
\hline Moyenne & 0,846 & 0,909 & 78,3 & 76,7 & 1,6 \\
\hline
\end{tabular}

* P : Présure de veau.

** SC : "Sure Curd »: Enzyme coagulant extrait d'Endothia parasitica.

L'action de la présure diffère de celle de l'enzyme coagulant sur un autre point, comme le montre la figure 2. Dans cette figure, on a porté la variation (en fonction du pourcentage de lactosérum écoulé) de la teneur en matières azotées solubles dans l'acide trichloracétique à 12 p. 100 (T.C.A. 12 p. 100) des fractions de lactosérum, 
présure ou SC, analysées : a) dès l'obtention ; b) après 3 jours de conservation à $2^{\circ} \mathrm{C}$. Dans le cas de la présure, les teneurs des deux séries d'échantillons, frais et conservés, sont demeurées très voisines. Mais dans le cas du lactosérum SC, la courbe correspondant aux échantillons conservés pendant 3 jours indique une teneur en matières azotées solubles dans le T.C.A. notablement plus élevée que celle correspondant au lactosérum juste après l'obtention.

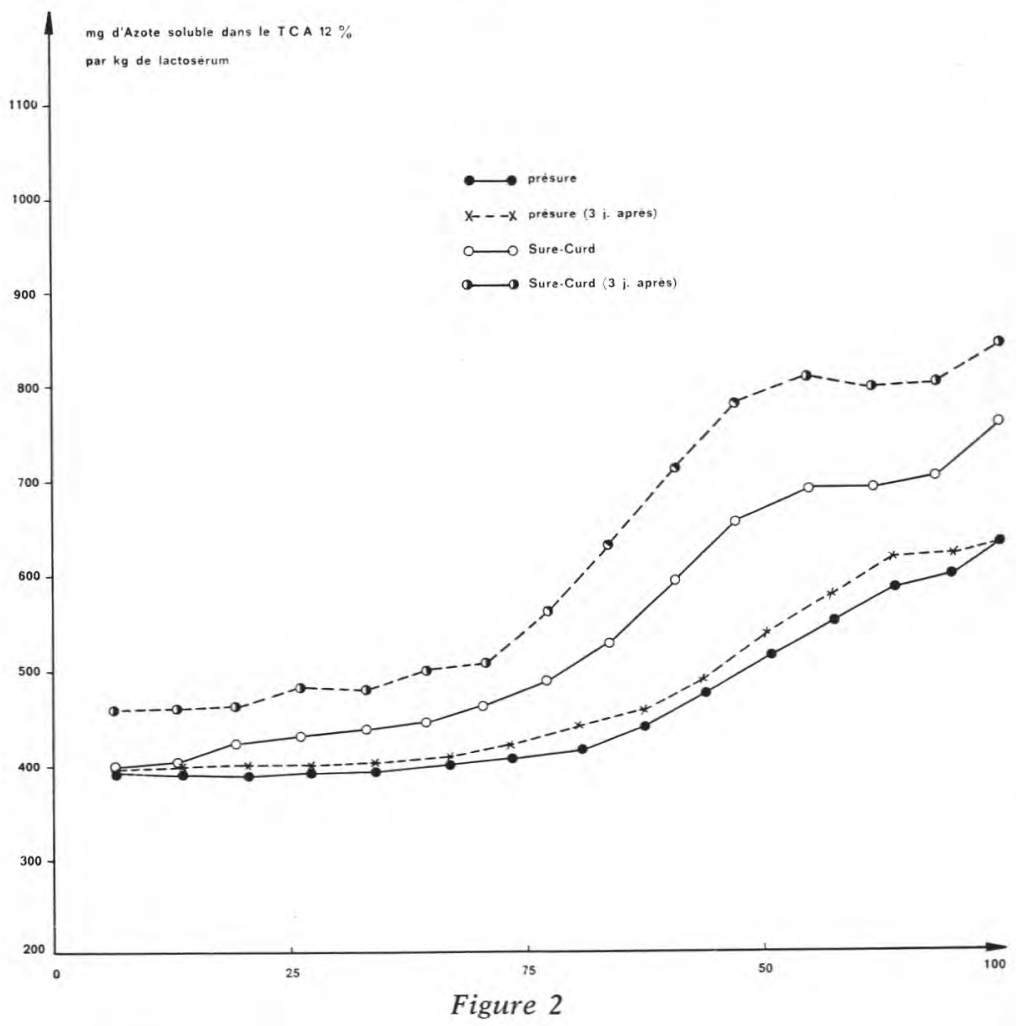

Variation de la teneur en azote soluble du lactosérum

(en abscisse p. 100 du lactosérum écoulé)

\section{DISCUSSION}

La coagulation du lait par la présure s'accompagne d'une protéolyse rapide mais limitée de la caséine. Les courbes de la figure 1 montrent que la phase dite de protéolyse générale non spécifique de la caséine (Kosikowski et Mocquot, 1958), succédant à cette phase de protéolyse limitée, débute vers $\mathrm{pH} 5,5$ (ce qui est tout à fait conforme aux résultats obtenus par Ledford et al., 1968) lorsque 60 p. 100 du lactosérum est écoulé ; elle se produit avec une vitesse notable puisqu'on a constaté, au cours des expériences, entre la première et la dernière fraction de lactosérum présure, une augmentation d'en- 
viron 15 p. 100 de la teneur en matières azotées totales. (Cette augmentation correspond à un peu plus de $0,1 \mathrm{~g}$ de matières azotées pour $100 \mathrm{~g}$ de lactosérum).

L'enzyme SC solubilise un peu plus de caséine que la présure. Cette caséine solubilisée s'écoule avec le lactosérum (environ 0,6 g de caséine solubilisée en plus par $\mathrm{kg}$ de lactosérum) et est donc perdue pour le fromage.

On peut admettre qu'en fromagerie de pâte molle, le poids total de lactosérum écoulé représente un peu plus de 80 p. 100 du poids de lait coagulé. Donc, pour $1 \mathrm{~kg}$ de lait mis en œuvre, les $800 \mathrm{~g}$ de lactosérum écoulé contiendront $0,6 \mathrm{~g} \times 0,8=0,48 \mathrm{~g}$, soit environ 0,5 g de caséine solubilisée en plus.

D'autre part, un grand nombre de résultats montrent que, toujours en fromagerie de pâte molle, on obtient $100 \mathrm{~g}$ de fromage affiné en partant de $0,84 \mathrm{~kg}$ de lait ayant la composition suivante : graisse $26 \mathrm{~g} / \mathrm{kg}$ et protéines $32 \mathrm{~g} / \mathrm{kg}$ (Maubois et Mocquot, 1969).

Avec un tel lait, coagulé par la présure, en moyenne 74 p. 100 des protéines passent dans le fromage (Mocquot et al., 1963), et celui-ci contient, dans $100 \mathrm{~g}$ de fromage affiné, $55 \mathrm{~g}$ d'eau, 20,7 g de graisse et 24,3 g d'extrait sec dégraissé dont 19,5 de protéines.

Avec l'enzyme SC, $0,5 \mathrm{~g}$ de ces protéines passeront dans le lactosérum pour chaque $\mathrm{kg}$ de lait coagulé, ou encore $0,42 \mathrm{~g}$ de protéines pour $0,84 \mathrm{~kg}$ de lait coagulé.

On sait que la plus grande partie de l'eau du fromage est retenue par les protéines (Mocquot et al., 1963) alors que le reste de la substance sèche et notamment la graisse n'en retiennent qu'une quantité plus faible. Supposons toutefois, en première approximation, que la quantité d'eau retenue par gramme soit la même, quel 55

que soit le constituant considéré, soit $-=1,22 \mathrm{~g}$ d'eau par gramme 45

de substance sèche. On voit que $0,42 \mathrm{~g}$ de protéines auraient retenu $(0,42 \times 1,22)$ soit $0,51 \mathrm{~g}$ d'eau. C'est donc au total $0,42 \mathrm{~g}+0,51 \mathrm{~g}=0,93 \mathrm{~g}$ de "fromage " qui sera " perdu " dans le lactosérum SC. On obtiendra seulement $100-0,93=99,07 \mathrm{~g}$ de fromage avec l'enzyme $\mathrm{SC}$ au lieu de $100 \mathrm{~g}$ avec la présure, soit une perte d'environ $1 \mathrm{p} .100$ sur le poids de fromage.

Comme nous l'avons indiqué, ce chiffre est un minimum en raison du fait que la quantité d'eau retenue par gramme de protéines est plus élevée que celle retenue par gramme de matière sèche du fromage. En fait la perte de fromage doit être supérieure à 1 p. 100 .

Pour le fromager, le rapport existant entre le prix de la présure et le prix de l'enzyme SC (ou de tout autre enzyme coagulant de remplacement) doit faire entrer en ligne de compte la diminution 
éventuelle de la quantité de fromage obtenue à partir d'une quantité déterminée de lait. Un calcul relativement simple* permet de montrer que le prix d'un enzyme coagulant provoquant une perte de rendement de 1 p. 100 en poids de fromage ne devrait pas dépasser le $1 / 6$ du prix de la présure pour compenser la perte de fromage.

L'augmentation notable de la quantité d'azote soluble du lactosérum SC au cours de sa conservation ( $c f$. figure 2) montre que l'enzyme SC exerce une action protéolytique marquée sur les matières azotées du lactosérum. Nous avons vérifié cette action de l'enzyme SC en préparant un lactosérum "isoélectrique " (précipitation de la caséine à pH 4,6 selon Aschaffenburg et Drewry, 1958), nous l'avons additionné d'enzyme SC (en même quantité que pour la coagulation du même volume de lait) et nous l'avons précipité par le T.C.A. 12 p. 100. La teneur en substances azotées solubles dans le T.C.A. 12 p. 100 , qui était initialement de $8,6 \mathrm{mg}$ d'azote pour $100 \mathrm{~g}$ de lactosérum, augmentait notablement lorsque le lactosérum était additionné de 0,02 p. 100 d'enzyme SC puis conservé 3 jours à $2^{\circ} \mathrm{C}$ : la teneur atteignait alors $13,6 \mathrm{mg}$ d'azote pour $100 \mathrm{~g}$ de lactosérum. L'action de la présure sur les matières azotées du lactosérum est, dans les mêmes conditions, très faible ou nulle.

Compte tenu du fait que les fromages renferment toujours une certaine quantité de lactosérum, compte tenu de la différence de

* Actuellement, le prix de la présure représente, en France, environ 0,2 p.100 du prix de vente des fromages à pâte molle (c'est une valeur qui paraît couramment admise).

$\mathrm{Si}$, avec $100 \mathrm{~kg}$ de lait mis en œuvre, on fabrique : 1) avec la présure, $\mathrm{P}_{1} \mathrm{~kg}$ de fromage ; 2 ) avec un enzyme coagulant, $\mathrm{P}_{2} \mathrm{~kg}$ de fromage ; si le prix de la présure utilisée par cette transformation représente une proportion " a * $\mathrm{du}$ prix de vente $(\mathrm{p})$ d'un $\mathrm{kg}$ de fromage et si « $\mathrm{x}$ » représente la proportion de fromage fabriqué en plus avec la présure, on peut écrire que, pour demeurer compétitif, le prix d'un enzyme coagulant doit être inférieur ou égal à la somme (prix de la présure + prix du fromage perdu), soit :

Prix de l'enzyme $\leqslant\left[a . P_{2}+\left(P_{1}-P_{2}\right)\right] p$

soit, en divisant de part et d'autre par le prix de la présure et en simplifiant,

$$
\frac{\text { prix de l'enzyme }}{\text { prix de la présure }} \leqslant 1+\frac{\left(P_{1}-P_{2}\right)}{a P_{2}}
$$

ou bien en remplaçant par $\mathrm{x}$, on obtient :

$$
\frac{\text { prix enzyme }}{\text { prix présure }} \leqslant 1+\frac{\mathrm{x}}{\mathrm{a}}
$$

Actuellement $\mathrm{a}=0,002$ et, pour l'enzyme $\mathrm{SC}, \mathrm{x}=0,01$ donc le rapport (prix enzyme/prix présure) doit être inférieur ou égal à :

$$
1+\frac{0,01}{0,002} \text { soit } 6
$$

ce qui veut dire que le prix de l'enzyme SC ne devrait pas dépasser le 1/6 de celui de la présure pour compenser la perte de fromage. 


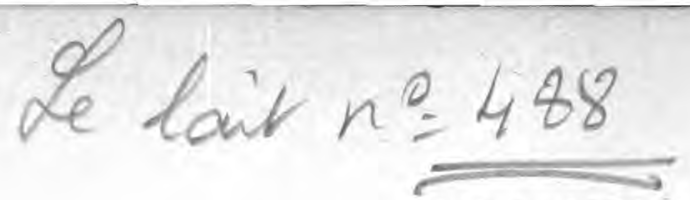

ER R A T U M

Dans l'article intitulé : "Action protéolytique d'un enzyme coagugulant comparée à celle de la présure » par J. L. Maubors et G. Mocouot, $\mathrm{n}^{\circ} 488$, p. 504 le premier paragraphe est remplacé par le suivant :

...éventuelle de la quantité de fromage obtenue à partir d'une quantité déterminée du lait. Un calcul relativement simple* permet de montrer que, le prix de vente de l'enzyme SC étant supposé, à force coagulante égale, le même que le prix actuel de la présure, la dépense imputable à l'emploi de cet enzyme, compte tenu de la perte de rendement de 1 p. 100 en poids de fromage qu'il provoque, se monte à 6 fois la dépense entraînée par l'emploi de la présure.

\section{La note en bas de page est remplacée par ce qui suit :}

* Actuellement, le prix de la présure représente, en France, environ 0,2 p. 100 du prix de vente des fromages à pâtes molles (c'est une valeur qui paraît couramment admise).

$\mathrm{Si}$, avec $100 \mathrm{~kg}$ de lait mis en œuvre, on fabrique : 1) avec la présure, $\mathrm{P}_{1} \mathrm{~kg}$ de fromage ; 2 ) avec un enzyme coagulant, $\mathrm{P}_{2} \mathrm{~kg}$ de fromage ; si le prix de l'enzyme coagulant est supposé, à force coagulante égale à celle de la présure, être le même que le prix de la présure ; si la dépense correspondant à l'emploi de la quantité de présure nécessaire pour coaguler $100 \mathrm{~kg}$ de lait représente une proportion " a " du prix de vente du fromage fabriqué (le prix d'un $\mathrm{kg}$ de fromage étant « $p ») ;$ si « $x$ » représente enfin la proportion de fromage fabriqué en plus avec la présure, on peut écrire que le coût d'emploi de l'enzyme coagulant " $\mathrm{C}_{\mathrm{F}}$ " est égal à la somme de la dépense correspondant à la quantité d'enzyme employé (c'est-à-dire par hypothèse la même dépense que celle correspondant à l'emploi de la présure " $\mathrm{C}_{\mathrm{P}} »=\mathrm{a} \mathrm{P}_{1} \mathrm{p}$ ) et de la perte résultant de la moindre quantité de fromage fabriqué soit :

$$
\mathrm{C}_{\mathrm{E}}=\mathrm{a} \mathrm{P}_{1} \mathrm{p}+\left(\mathrm{P}_{1}-\mathrm{P}_{2}\right) \mathrm{p}
$$

en divisant de part et d'autre par le coût de présure " $C_{P}$ " et en simplifiant

$$
\frac{\mathrm{C}_{\mathrm{E}}}{\mathrm{C}_{\mathrm{P}}}=1+\frac{\mathrm{P}_{1}-\mathrm{P}_{2}}{\mathrm{a} \mathrm{P}_{1}}
$$

puis en remplaçant par $\mathrm{x}$, on obtient :

$$
\frac{\mathrm{C}_{\mathrm{E}}}{\mathrm{C}_{\mathrm{P}}}=1+\frac{\mathrm{x}}{\mathrm{a}}
$$

Actuellement, $\mathrm{a}=0,002$ et, pour l'enzyme SC, $\mathrm{x}=0,01$; donc le rapport des coûts d'emploi de l'enzyme coagulant et de la présure est égal à :

$$
1+\frac{0,01}{0,002} \text { soit } 6
$$

Ceci revient à dire que la dépense imputable à l'emploi de l'enzyme SC est dans l'hypothèse actuelle égale à 6 fois la dépense entraînée par l'emploi de la présure.

Ceci montre également que, même dans le cas où l'enzyme serait gratuit, la dépense imputable à son emploi serait encore égale à 5 fois celle due à l'emploi de la présure. 
composition qui sépare la paracaséine des protéines du lactosérum [notamment en ce qui concerne la teneur en certains acides aminés soufrés (cystine et cystéine)], on peut se demander si cette protéolyse des matières azotées du lactosérum est, ou n'est pas, susceptible d'entraîner, dans des conditions d'affinage déterminées, des différences de qualité organoleptique entre les fromages fabriqués avec l'enzyme coagulant SC et ceux fabriqués avec la présure classique. Il n'est d'ailleurs pas possible de prévoir, a priori, si cette différence sera en faveur ou au détriment de l'un ou l'autre enzyme (présure ou SC) en ce qui concerne la qualité finale du fromage. On peut simplement dire que des expériences préalables paraissent nécessaires.

\section{R és u m é}

Le " rendement » en fromage à pâte molle d'un même lait coagulé par la présure d'une part, par " l'enzyme coagulant » extrait d'Endothia parasitica d'autre part, est plus élevé dans le cas de la présure (différence moyenne 1 p. $100 \mathrm{du}$ poids de fromage obtenu). Cette différence provient d'une protéolyse plus marquée qui intervient au cours de l'égouttage dans le cas de l'enzyme coagulant. Par ailleurs l'enzyme coagulant exerce une action protéolytique sur les protéines du lactosérum, ce que ne fait pas la présure.

Les implications de ces observations sur le plans technologique et économique sont discutées.

\section{S u m m a ry}

The cheese yield (Camembert type) obtained from the same milk is higher when the milk is clotted with calf rennet than when it is clotted with the enzyme extracted from Endothia parasitica. The difference in yield is equal, on the average, to 1 per cent of the weight of cheese and is due to the more intense proteolysis which occurs during whey drainage. It is also shown that the enzyme from E. parasitica exerts a proteolytic effect on the whey proteins, while calf rennet does not.

The technological and economical consequences from these observations are discussed.

\section{Références bibliographiques}

[1] Garnier (J.), Mocouot (G.), Ribadeau-Dumas (B.) et Maubois (J. L.). - Coagulation du lait par la présure : Aspects scientifiques et technologiques. Ann. Nutr. Alim., 1968, 22, B 495 - B 552.

[2] Kosikowski (F. V.) et Mocouot (G.). - Progrès de la technologie du fromage. Etudes agricoles de la F.A.O., Rome, 1958.

[3] LedFord (R. A.) O'Sullivan (A. C.) et Nath (K. R.). - Residual Casein Fractions in Ripened Cheese Determined by Polyacrylamide Gel Electrophonesis. J. Dairy Sc., 1966, 49, p. $1098-1101$. 
[4] Ledford (R. A.), Chen (J.H.) et NATH (K. R.). - Degradation of Casein Fractions by Rennet Extract. J. Dairy Sc., 1968, 51, p. 792-794.

[5] Sardinas (J. L.). - 1968, U.S. Patent 3275453.

[6] Naudts (M.). - Rapport sessions annuelles. Fédér. Internat. Laiterie, 1967.

[7] Alais (C.) et NovaK (G.). - Etude d'un enzyme coagulant microbien dérivé de Endothia parasitica : I. Propriétés biochimiques de l'enzyme coagulant Pfizer et propriétés rhéologiques des caillés formés dans le lait. Le Lait, 1968, 48, p. 393.

[8] Ramet (J. P.), Alais (C.) et Weber (F.). - Etude d'un enzyme coagulant microbien dérivé de Endothia parasitica : II. Fabrications expérimentales de fromages à pâte molle et à pâte cuite avec l'enzyme coagulant Pfizer. Le Lait, 1969, 49, p. 40-52.

[9] Sardinas (J. L.). - Rennin enzyme of Endothia parasitica. Appl. Microbiol., 1968,16 , p. 248.

[10] Maubois (J. L.) et Mocouot (G.). - Comment ramener à la même teneur en substance sèche des fabrications de fromage en vue de comparer les " rendements » respectifs du lait en fromage. Rev. Lait. Franç., 1967, 239, p. 15-18.

[11] Aschaffenburg (R.) et Drewry (J.). - New procedure for the routine determination of the various non-casein proteins of milk. XV $V^{\mathrm{e}}$ Cong. Int. Lait., Londres, 1959, 3, p. $1631-1637$.

[12] Maubois (J. L.) et Mocouot (G.). - 1969. Résultats non publiés.

[13] White (J.C.D.) et Davies (D. T.). - The relation between the chemical composition of milk and the stability of the caseinate complex. J. Dairy Res., 1958, 25, p. 236.

(Reçu pour publication en juin 1969). 